\title{
Conservative Management of the Isolated Mandibular Coronoid Process Fracture
}

\author{
(10) Ayşenur GENÇ, id Osman KÜÇÜKÇAKIR, id Rüştü Cem TANYEL
}

İstanbul University Faculty of Dentistry, Department of Oral and Maxillofacial Surgery, İstanbul, Turkey

\begin{abstract}
Fractures of the coronoid process are uncommon and can easily be missed. Coronoid fracture may manifest as simple, linear line with minimal displacement. If the periosteum is traumatized, the degree of displacement may increase. Restricted mouth opening and mandibular movement, malocclusion, and swelling below the zygomatic arch may be evident. The decision of treatment plan should be based on the fracture pattern, time of the fracture, the presence or absence of concomitant fractures, and clinical symptoms. Coronoid fractures are generally managed conservatively, a few cases require surgical intervention. A rare case of fracture of the coronoid process caused by trauma of the temporalis muscle is described.
\end{abstract}

Keywords: Coronoid process, mandible, fracture

\section{Introduction}

The incidence of coronoid fractures is reported to be $1-2 \%$ in all facial fractures (1). Etiological factors are stated to include traffic accident, fall, attack, third molar tooth extraction and sagittal split osteotomy (2-4).

Coronoid fractures are usually simple and linear and have little displacement. If the periosteum is injured, this displacement rate may increase with the contraction of the temporal muscle (3). Its definite diagnosis is established by considering patient history, clinical examination and radiographic examination. Although conservative approaches are generally used in its treatment, surgical intervention is rarely required (5).

In this report, a case of isolated coronoid process fracture and its treatment was presented with the review of the literature.

\section{Case Report}

A systemically healthy 34-year-old male patient presented to our clinic with the complaints of pain in the left temporomandibular joint, trismus, and restricted chewing. It was learned from the patient's history that head trauma occurred as a result of falling 15 days ago. In the oral examination, restricted mouth opening $(7 \mathrm{~mm})$ and pain, tenderness in the left retromolar region, ramus and zygomatic arch with palpation were recorded (Figure 1). There was no irregularity in the occlusal relationship of the patient. Extraoral examination revealed no soft tissue irregularity and bone contour disorder.

Radiological examination revealed a unilateral, isolated, linear, anteroposterior oblique and slightly displaced fracture in the left mandibular coronoid process (Figures 2, 3). The presence of mandibular and midface fractures accompanying coronoid process fracture was not detected.

Address for Correspondence: Ayşenur GENÇ, İstanbul University Faculty of Dentistry, Department of Oral and Maxillofacial Surgery, İstanbul, Turkey

E-mail: anuruzun@gmail.com ORCID ID: orcid.org/0000-0002-0771-9793 
The patient was informed and informed consent was obtained and conservative treatment was preferred because of the slight displacement of the fractured bone segment and the simple, linear fracture line. The lower and upper jaws were fixed with intermaxillary fixation (IMF) and elastics for 15 days, considering the patient's symptoms and the 15-day period following the trauma. As a result of no change in the position in the fracture fragment, IMF application was completed at the end of $14^{\text {th }}$ day, physical therapy exercises were continued and a soft diet was suggested.

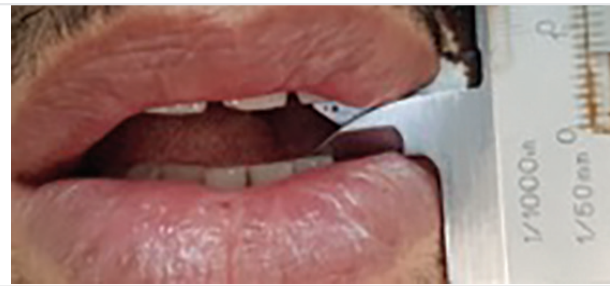

Figure 1. Mouth opening measurement value before the treatment $(7 \mathrm{~mm})$

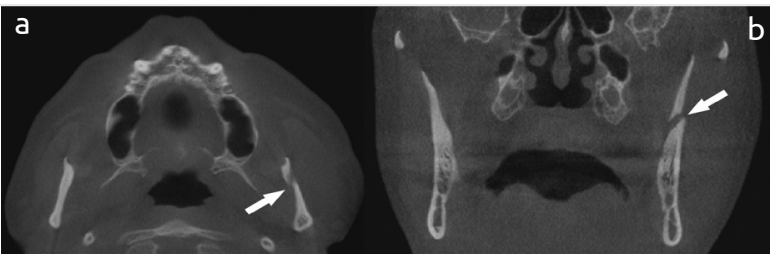

Figure 2. In the axial (a) and coronal (b) sections, the left coronoid fracture line is indicated by the white arrow

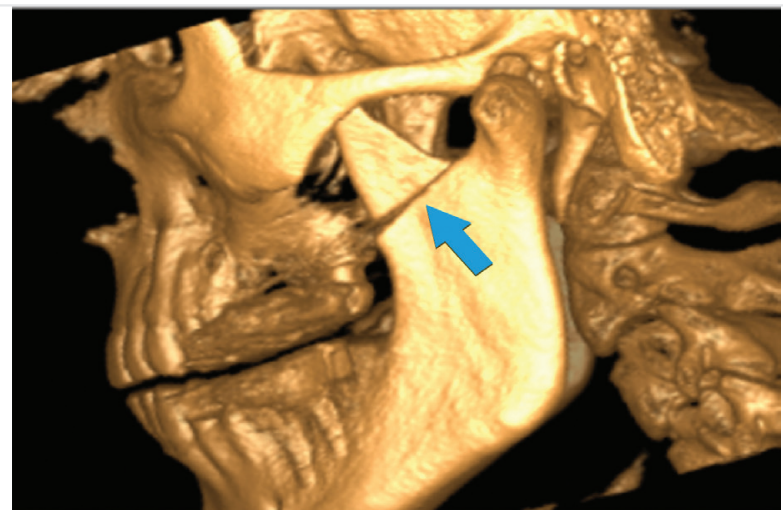

Figure 3. Left coronoid process fracture is observed on a three-dimensional model generated from computerized tomography recordings (blue arrow)

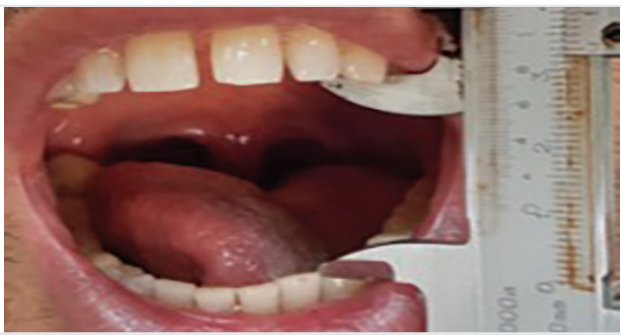

Figure 4. Mouth opening measurement value after the treatment $(32 \mathrm{~mm})$
At the end of four-week follow-up, the position of the fracture fragment was observed to be stable in the tomographic images. The mouth opening value was measured as $35 \mathrm{~mm}$ after the treatment (Figure 4). The treatment was completed with complete elimination of the patient's complaints and achievement of an acceptable anatomical, functional and aesthetical result.

\section{Discussion}

Isolated coronoid process fractures without an accompanying maxillofacial fracture, which was the diagnosis of our case, are rarely seen and there are limited number of reports on their treatment according to the authors' knowledge (6).

Coronoid process is a structure that is anatomically protected by the zygomatic complex and muscles. Because it is not associated with cranial bones, the etiology of fracture does not involve indirect trauma. Coronoid fractures are often caused by a direct, penetrating trauma or sudden and severe contraction of the temporal muscle during trauma (7). The temporal muscle starts from the temporal fossa and attaches to the medial surface of the coronoid process. Myotatic reflex triggered by tension in a muscle causes excitation of muscle spindles, contraction of muscle skeletal fibers and synergistic muscles. Therefore, a blunt trauma to the temporal region plays a role in initiating temporal muscle contraction. In such a case, if the teeth are not in an occlusal relationship, the coronoid process is exposed to significant stress and fracture may occur (8). Although our case could not confirm the jaw position during injury, it can be said that acute reflex contraction due to trauma in the temporal muscle causes coronoid fracture.

Depending on the severity of the injury, symptoms such as malocclusion, limitation of lower jaw movements, and swelling of the zygomatic arch may occur. Since the fracture is mostly accompanied by zygomatic bone fracture, the main cause of trismus is the zygomatic arch dislocation $(2,4)$. The main cause of isolated fractures is muscle spasm because the coronoid process is the place of the attachment of temporal muscle anteriorly and masseter muscle fibers laterally. In our case, fractured coronoid process segment without displacement and dislocation caused restricted mouth opening due to temporal and masseter muscle spasm associated with trauma.

It is recommended that treatment protocol be determined according to the degree of displacement of the fracture fragment and clinical symptoms $(3,9)$. In patients with severe malocclusion and severe pain, IMF can be applied up to 4 weeks. For simple coronoid fractures without displacement or malocclusion, treatment is not recommended because temporal muscle spasm shows the splint effect and causes the segment to remain in stable position (10). In our case, after 14-day IMF treatment, lower jaw mobilization was provided and soft diet and physical therapy exercises were given to prevent osseous adhesions.

If trismus persists after conservative treatment, coronoidectomy is recommended because of the risk of osseous junction between the coronoid process and the zygomatic arch. In addition, rigid internal fixation can be performed in patients with 
severe displacement of the fracture fragment, accompanying midfacial or mandibular fractures, and in patients who cannot undergo IMF for a long time $(1,5)$. It has been reported that coronoidectomy performed by intraoral approach is superior to rigid internal fixation treatment which has disadvantages such as facial scar, facial nerve damage, long operation time, and platescrew cost $(5,9)$.

In conclusion, although coronoid fractures occur rarely, treatment approach should be according to fracture pattern, time of fracture occurrence, presence of accompanying fracture, and severity of clinical symptoms. Considering fracture stability and the risk of post-traumatic ankylosis during treatment, it is important to continue rehabilitation with physical therapy exercises.

\section{Etihics}

Informed Consent: Informed consent was obtoined from the patient.

Peer-review: Externally peer-reviewed.

\section{Authorship Contributions}

Consept: A.G., OK., R.C.T., Design: A.G., OK., R.C.T., Data Collection or Processing: A.G., OK., R.C.T., Analysis or Interpretation: A.G., OK., R.C.T., Literature Search: A.G., OK., R.C.T., Writing: A.G., OK., R.C.T.,

Conflict of Interest: No conflict of interest was declared by the authors.

Financial Disclosure: The authors declared that this study received no financial support.

\section{References}

1. Boffano P, Kommers SC, Roccia F, Gallesio C, Forouzanfar T. Fractures of the mandibular coronoid process: A two centres study. Journal of Craniomaxillofacial Surgery 2014;42:1352-5.

2. Delantoni A, Antoniades I. The iatrogenic fracture of the coronoid process of the mandible. A review of the literature and case presentation. Cranio 2010;28:200-4.

3. Rapidis AD, Papavassiliou D, Papadimitriou J, Koundouris J, Zachariadis N. Fractures of the coronoid process of the mandible. An analysis of 52 cases. Int J Oral Surg 1985;14:126-30.

4. de Santana Santos T, Frato R, Martins- Filho PR, Vajgel A, de Albuquerque Maranhão-Filho AW, de Oliveira E Silva ED. Fracture of the coronoid process, sphenoid bone, zygoma, and zygomatic arch after a firearm injury. J Craniofac Surg 2011;22:34-7.

5. Shen L, Li J, Li P, Long J, Tian W. Mandibular coronoid fractures: Treatment options. Int J Oral Maxillofac Surg 2013;42:721-6.

6. Natvig P, Sicher H, Fodor P. The rare isolated fracture of the coronoid process of the mandible. Plast Reconstr Surg 1970;46:168-72.

7. Baykul T, Aydin MA, Aksoy MC, Findık Y. Unusual unilateral fracture of the condylar and coronoid processes of the mandible. J Clin Imaging Sci 2014;4:3.

8. Philip M, Sivarajasingam V, Shepherd J. Bilateral reflex fracture of the coronoid process of the mandible. A case report. Int J Oral Maxillofac Surg 1999; 28: 195-196.

9. Takenoshita Y, Enomoto T, Oka M. Healing of fractures of the coronoid process: report of cases. J Oral Maxillofac Surg 1993;51:200$4 . æ c ̧$

10. Waknis PP, Mishra T. Mandibular coronoid fractures: treatment options. Int J Oral Maxillofac Surg 2014;43:132. 